\title{
TOXICITY OF HUMAN PHARMACEUTICALS AND PERSONAL CARE PRODUCTS TO BENTHIC INVERTEBRATES
}

\author{
Ève B. Dussault, $\dagger$ Vimal K. Balakrishnan, $\$$ Ed Sverko,§ Keith R. Solomon, $†$ and Paul K. Sibley $\dagger^{*}$ \\ $\dagger$ Department of Environmental Biology, University of Guelph, Guelph, Ontario N1G 2W1, Canada \\ †Aquatic Ecosystem Protection Research Division, Environment Canada, Burlington, Ontario L7R 4A6 \\ §National Laboratory for Environmental Testing, Environment Canada, Burlington, Ontario L7R 4A6
}

(Received 8 June 2007; Accepted 6 August 2007)

\begin{abstract}
Despite concerns about potential risks associated with the presence of pharmaceuticals and personal care products (PPCPs) in the environment, few toxicological data address the effects of these compounds. In aquatic systems, which often represent the final repository for PPCPs, increasing toxicological information regarding aquatic biota is improving our capacity to assess potential risks. However, responses of key biota, such as benthic invertebrates, have not been investigated as widely. In the present study, we examined the toxicity of four PPCPs- the lipid regulator atorvastatin (ATO), the antiepileptic drug carbamazepine (CBZ), the synthetic hormone $17 \alpha$-ethinylestradiol $\left(\mathrm{EE}_{2}\right)$, and the antimicrobial triclosan (TCS) - to the midge Chironomus tentans and the freshwater amphipod Hyalella azteca in 10-d waterborne exposures. The toxicity of the four compounds varied between 0.20 and $47.3 \mathrm{mg} / \mathrm{L}$ (median lethal concentration), with a relative toxicity ranking of TCS $>\mathrm{EE}_{2}>\mathrm{ATO}>\mathrm{CBZ}$. Hyalella azteca was more sensitive than $C$. tentans to these compounds. The toxicity data were used in a hazard quotient approach to evaluate the risk posed by the four PPCPs to benthic invertebrates and other aquatic organisms. For each compound, a hazard quotient was calculated by dividing the lowest toxicity value by the highest exposure value found in the literature, to which an uncertainty factor was applied. With hazard quotients of 3.55 to 11.5 , we conclude that potential risks exist toward benthic invertebrates for the toxicity of TCS and CBZ and that further investigations of these compounds are required to characterize more completely the risks to benthic organisms. In contrast, our data also indicate that considering the low concentrations currently detected in the environment, $\mathrm{ATO}$ and $\mathrm{EE}_{2}$ pose negligible risks to benthic invertebrates.
\end{abstract}

Keywords-Benthic invertebrates Pharmaceuticals Personal care products Toxicity

\section{INTRODUCTION}

In recent years, the environmental occurrence of pharmaceuticals and personal care products (PPCPs) has been a source of growing concern. The vast increase in production and usage of PPCPs has contributed to their prevalence in surface waters, a problem that has been exacerbated by existing water treatment facilities that are not designed to eliminate these compounds from waste streams $[1,2]$.

Release of PPCPs into aquatic systems and groundwater mainly arises from the excretion of the drug or its metabolites from the target organism, inappropriate disposal of expired or unused medication, incomplete degradation during sewage treatment, and/or leaching from soils following land application of biosolids $[1,3,4]$. Increasingly, studies report detectable concentrations of PPCPs and their metabolites in surface water, sewage effluent, soils, sediments, groundwater, and drinking water [1-3,5]. Moreover, continuous consumption and release of PPCPs into aquatic systems contribute to their pervasiveness in the environment. Lastly, a unique aspect that also must be considered when assessing potential risks of PPCPs in the environment is that they are designed to elicit specific effects in target organisms and, hence, possess considerable biological activity [1].

Several studies have investigated acute effects of PPCPs on aquatic organisms [6-9]. The effects on benthic invertebrates, however, have not been widely investigated despite

* To whom correspondence may be addressed (psibley@uoguelph.ca).

Published on the Web 10/11/2007. their essential role in aquatic food webs and the potential for sediments to serve as a repository for anthropogenic contaminants $[10,11]$. Therefore, the objective of the present study was to evaluate the toxicity of four commonly used PPCPs on two benthic invertebrates, the midge Chironomus tentans and the freshwater invertebrate Hyalella azteca, using 10-d, wateronly exposures. These data were then combined with environmental occurrence data to calculate a hazard quotient (HQ) and, thereby, provide a worst-case scenario assessment of the risks these compounds may pose to benthic organisms.

The selection of PPCPs for testing was based on Canadian usage data, chemical persistence, availability of analytical methods, and previous research within our group. This resulted in the selection of four chemicals.

Atorvastatin (ATO) is the most widely prescribed lipid regulator in Canada [12], and it has been detected in both sewage effluent and surface water $[13,14]$. Studies have revealed the phytotoxic effect of ATO to aquatic macrophytes at concentrations as low as $26 \mu \mathrm{g} / \mathrm{L}[15]$.

Carbamazepine (CBZ) is an antiepileptic drug, but is also used for treatment of psychological disorders and chronic pain [16]. Low degradation rates upon sewage treatment have been reported; thus, CBZ is commonly detected in sewage effluent and surface water, and was also detected in groundwater $[3,17,18]$. Its environmental persistence raises concerns about potential effects on nontarget organisms.

The synthetic hormone $17 \alpha$-ethinylestradiol $\left(\mathrm{EE}_{2}\right)$, which is used for birth control and hormone replacement therapy, has been investigated extensively in vertebrates and has feminizing effects in fish at concentrations currently detected in 
Table 1 . Water-quality characteristics of test water monitored throughout the experiments ${ }^{\mathrm{a}}$

\begin{tabular}{lcr}
\hline & Chironomus tentans & Hyalella azteca \\
\hline $\mathrm{pH}$ & $8.4 \pm 0.12(254)$ & $7.7 \pm 0.30(228)$ \\
Temperature $\left({ }^{\circ} \mathrm{C}\right)$ & $21.9 \pm 0.73(255)$ & $22.4 \pm 1.13(228)$ \\
Dissolved oxygen $(\mathrm{mg} / \mathrm{L})$ & $7.9 \pm 0.39(243)$ & $6.5 \pm 1.33(228)$ \\
Conductivity $(\mathrm{mS} / \mathrm{cm})$ & $606 \pm 57(132)$ & $395 \pm 20(192)$ \\
Alkalinity $(\mathrm{mEq})$ & $0.35 \pm 0.100(23)$ & $0.11 \pm 0.008(58)$ \\
Hardness $(\mathrm{mmol})$ & $0.25 \pm 0.081(26)$ & $0.13 \pm 0.004(59)$ \\
Ammonia $(\mathrm{mg} / \mathrm{L})^{\mathrm{b}}$ & $1.4 \pm 0.69(18)$ & $0.3 \pm 0.12(23)$ \\
\hline
\end{tabular}

a Values are presented as the mean \pm standard deviation. The number of samples is in parentheses. $\mathrm{mS} / \mathrm{cm}=$ milli-Siemens per centimeter.

${ }^{\mathrm{b}}$ Measurements performed on day-10 water residues.

the environment [19]. Until recently, comparatively few studies have examined its potential effects on nonvertebrate species.

Triclosan (TCS) has been used for more than 35 years as an antimicrobial and antifungal agent, and is a common constituent of household and personal care products, including soaps, shampoos, deodorants, and detergents. Its current widespread usage has raised concerns regarding possible effects on bacterial resistance, suggesting that potential effects of TCS on benthic invertebrates should be investigated.

\section{MATERIALS AND METHODS}

\section{Chemicals}

Acetone (distilled in glass), acetonitrile (MeCN; high-performance liquid chromatography grade), methanol (MeOH; high-performance liquid chromatography grade), dichloromethane (distilled in glass), toluene (distilled in glass), and silica gel (particle size, 100-200 $\mu \mathrm{m}$ ) were purchased from Caledon (Georgetown, ON, Canada). Pentafluorobenzylbromide (purity, $\geq 99 \%$ ) was obtained from Sigma-Aldrich (Oakville, ON, Canada).

Atorvastatin (purity, $\geq 99 \%$ ) was obtained from Rugao Foreign Trade (Shanghai, Jiangsu, China). Carbamazepine (purity, $\geq 99 \%$ ) was supplied by China Jiangsu Textiles (Nanjing, Jiangsu, China). 17 $\alpha$-Ethinylestradiol (purity, $\geq 98 \%$ ) and TCS (purity, $\geq 97 \%$ ) were acquired from Sigma-Aldrich.

Isotopically labelled ${ }^{2} \mathrm{D}_{2}-17 \beta$-estradiol (atomic purity, $>98 \%$ ) was obtained from Sigma-Aldrich, and ${ }^{2} \mathrm{D}_{3}$-ibuprofen (atomic purity, $\geq 99 \%$ ), used as a laboratory surrogate because isotopically labeled TCS was not available at that time, was purchased from CDN Isotopes (Pointe-Claire, QC, Canada).

\section{Test organisms}

A laboratory culture of $C$. tentans (now Chironomus dilutus), obtained from the U.S. Environmental Protection Agency (EPA; Duluth, MN, USA), was maintained in reconstituted water at the University of Guelph (Guelph, ON, Canada) following U.S. EPA guidelines [10]. New egg masses were seeded before each experiment, and 12-d-old animals were used in all toxicity tests. All experiments were performed in reconstituted water.

Hyalella azteca were obtained from Environment Canada (Burlington, ON, Canada). Culture maintenance and testing were performed in reconstituted standard artificial medium [20] at the University of Guelph following U.S. EPA guidelines [10]. Animals were selected for testing at 7 to 14 days of age.

\section{Toxicity tests}

The toxicity of each compound was investigated individually using 10-d assays following U.S. EPA guidelines [10].
All experiments were conducted in 300-ml tall-form beakers, to which $50 \mathrm{ml}$ of sand (particle size, 250-500 $\mu \mathrm{m}$ ) were added in the $C$. tentans experiments. A small piece of cotton gauze was added in the $H$. azteca experiments to serve as substrate [20]. For each toxicity test, either eight or nine concentrations were used (seven concentrations plus control; a $0.2 \% \mathrm{MeOH}$ control was added for $\mathrm{EE}_{2}$ and TCS tests to aid dissolution into the aqueous phase). The number of replicates $(n=4-5)$ and number of animals added to each beaker $(n=9-10$ for C. tentans and 8-15 for $H$. azteca) depended on animal availability at the commencement of each test.

All tests were conducted under static-renewal conditions, with water renewals performed every $48 \mathrm{~h}$. The test containers were aerated continuously during the $C$. tentans assay, and $\mathrm{pH}$, temperature, dissolved oxygen, and conductivity were monitored throughout the experiments using a portable meter (Hach, Loveland, CO, USA) (Table 1). Water hardness, alkalinity and ammonia were measured by colorimetric assay (Hach) at the beginning and end of the experiments and are reported in Table 1. Water samples were collected for residue analysis. On experiment completion, surviving animals were counted, dried, and weighed for growth calculation using ashfree dry weight for $C$. tentans and dry weight for $H$. azteca.

\section{Analytical chemistry}

Atorvastatin and carbamazepine. Residue samples were collected before water renewal and frozen in glass vials for analysis. Quantification of ATO and CBZ was performed using an isocratic high-performance liquid chromatograph equipped with an ultraviolet detector at room temperature, using a Waters 600S pump (Waters, Milford, MA, USA) fitted with a Genesis C-18 reverse-phase column (length, $250 \mathrm{~mm}$; inner diameter, $4.6 \mathrm{~mm}$; film thickness, $4 \mu \mathrm{m}$; Jones Chromatography, Deerfield, IL, USA) and a Waters 996 photodiode-array detector. Target analytes were detected at wavelengths of 250 $\mathrm{nm}$ (ATO) and $290 \mathrm{~nm}$ (CBZ). A flow rate of $1 \mathrm{ml} / \mathrm{min}$ was used for all analyses. The mobile phase consisted of $60 \%$ MeCN:40\% buffer (10 mM potassium phosphate monobasic, adjusted to $\mathrm{pH} 3$ using $o$-phosphoric acid) for ATO analysis and 40\% MeCN:60\% buffer for CBZ analysis.

\section{$17 \alpha$-Ethinylestradiol}

Water residue samples were either frozen pending analyses or preconcentrated by solid-phase extraction (recovery, $87 \%$ $\pm 4.8 \%$ [mean \pm standard error of the mean, $n=6$ ]; Supelco ENVI-18; Sigma-Aldrich). Analyses were performed by liquid chromatography-tandem mass spectrometry (Waters 2695 separation module, Waters Quattro Ultima Micromass). Separation was achieved using a mobile phase consisting of a mixture of $\mathrm{MeCN}$ and $\mathrm{H}_{2} \mathrm{O}$ operated at a flow rate of $200 \mu \mathrm{l} / \mathrm{min}$. The 
gradient characteristics were 0 to $5 \mathrm{~min}$ at $60 \% \mathrm{MeCN}, 5$ to $7.5 \mathrm{~min}$ at $80 \% \mathrm{MeCN}$, and 7.5 to $10 \mathrm{~min}$ at $60 \% \mathrm{MeCN}$. A postinjection base of $0.5 \%$ ammonium carbonate was added at a rate of $10 \mu \mathrm{l} / \mathrm{min}$ and facilitated detection of the target compound. The mass spectrometer was operated in negativeelectrospray mode with a cone voltage of $20 \mathrm{kV}$, collision energy of $37 \mathrm{eV}$, parent ion $295.1 \mathrm{~m} / \mathrm{z}$, daughter ions $145.0 \mathrm{~m} / \mathrm{z}$ (quantitation) and $159.0 \mathrm{~m} / z$ (confirmation), and retention time of $2.6 \mathrm{~min}$. An internal standard of ${ }^{2} \mathrm{D}_{2}-17 \beta$-estradiol served to correct for variations in ionization efficiency.

\section{Triclosan}

Samples were acidified to $\mathrm{pH} 2$ with $50 \%$ sulfuric acid and preserved by addition of 50 to $100 \mathrm{ml}$ of dichloromethane. Samples were refrigerated for less than two weeks pending extraction. After addition of a laboratory surrogate, water samples were extracted by liquid-liquid extraction in dichloromethane and esterified using 5\% pentafluorobenzylbromide in acetone at $60^{\circ} \mathrm{C}$. After cleanup through $5 \%$ deactivated silica gel, target analytes were isolated using $5 \% \mathrm{MeOH}$ in toluene and analyzed by negative-ion chemical ionization gas chromatography-mass spectrometry using an Agilent 6890 gas chromatograph equipped with a HP5MS column (length, 30 $\mathrm{m}$; inner diameter, $0.25 \mathrm{~mm}$; film thickness, $25 \mu \mathrm{m})$ and a 5973 mass-selective detector (Agilent Technologies, Palo Alto, CA, USA). Helium was used as the carrier gas at a flow of $1.2 \mathrm{ml} / \mathrm{min}$, and methane was the reagent gas providing negative-ion chemical ionization. Average method recovery was $100 \% \pm 2.4 \%$ (mean \pm standard error of the mean, $n=74$ ).

\section{Statistical analyses}

Concentrations lethal to $50 \%$ (LC50), $25 \%$, and $10 \%$ of organisms as well as concentrations producing effects on $50 \%$ (EC50), 25\%, and 10\% of organisms were estimated using four regression models (linear, exponential, Gompertz, and logistic). All estimates were based on measured concentrations. For each model, all data were tested to ensure that they conformed to the assumptions of normality and homoscedasticity using the Shapiro-Wilk statistic and by plotting predicted values versus residuals, respectively. The studentized residuals were compared to the critical values for approximate tests of outliers. Data that failed to meet the assumptions were transformed using either a log transformation (concentration data) or a square root or arcsine-square root transformation (survival and growth data). The model that best fit the data based on coefficient of determination and conformation to the assumptions of the analysis of variance was selected. All computations were performed using $\mathrm{SAS}^{\circledR}$ software (Ver 9.1; SAS institute, Cary, NC, USA).

\section{Hazard quotient}

Data from the present study were used to calculate a hazard quotient (HQ) for each chemical investigated using the specifications provided in the Environment Canada guidance document [21]. The calculation used was HQ = (exposure/effect).UF, where exposure was the greatest concentration in surface water reported in the literature and UF was the uncertainty factor. The effect measure was the lowest measured LC50 or EC50 from the present study. Together, the exposure and effects data therefore represent worst-case scenarios. For all calculations, a UF of 1,000 was first selected for the conversion of our critical toxicity values to estimated no-effect values (two organisms), as suggested in the Environment Can- ada guidelines [21]. A second HQ was also estimated by the incorporation of data from other studies, thus allowing us to reduce the UF to 100 , because these HQ estimates were based on comparisons of acute toxicity data using three or more taxa [21].

\section{RESULTS AND DISCUSSION}

\section{Toxicity}

Of the four PPCPs tested, TCS was the most toxic compound, followed by $\mathrm{EE}_{2}$, ATO, and $\mathrm{CBZ}$, for both $C$. tentans and H. azteca (Tables 2 and 3 and Figs. 1 and 2). Concentrations required to cause a $50 \%$ effect (survival or growth) varied between 0.2 and $47.3 \mathrm{mg} / \mathrm{L}$ (Tables 2 and 3).

Hyalella azteca was significantly more sensitive than $C$. tentans, with the exception of the growth effects of $\mathrm{CBZ}$, for which the EC50 of C. tentans was $9.5 \mathrm{mg} / \mathrm{L}$, compared to 5.0 $\mathrm{mg} / \mathrm{L}$ for $H$. azteca, with overlapping $95 \%$ confidence intervals, and with the exception of the toxicity of TCS, which was similar (Table 2 and Table 3).

For all four PPCPs, survival of $C$. tentans and $H$. azteca followed typical concentration-response relationships (Figs. 1 and 2). In $C$. tentans, growth was a more sensitive indicator of toxicity than survival (Table 2 and Fig. 1). In contrast, growth in $H$. azteca was not more sensitive than survival (Table 3 and Fig. 2). The smaller size and growth rate of $H$. azteca (average dry wt of $0.06 \mathrm{mg}$ by the end of the experiments, compared with $0.95 \mathrm{mg}$ for $C$. tentans) make differences more difficult to detect. For this reason, Borgmann [20] suggested that longer time intervals or a greater number of replicates may be more appropriate for detecting the more subtle cumulative effects of growth in H. azteca.

\section{Atorvastatin}

Atorvastatin was approximately 10 -fold more toxic to $H$. azteca (LC50, $1.5 \mathrm{mg} / \mathrm{L}$ ) than to C. tentans (LC50, 14.3 $\mathrm{mg} / \mathrm{L})$ (Tables 2 and 3). Few other studies have investigated the effects of this compound; among others, 7-d EC50s of 38 to $214 \mu \mathrm{g} / \mathrm{L}$ were reported for the duckweed Lemna gibba $[15,22]$. To the best of our knowledge, the present study is the first to report invertebrate toxicity.

Currently, few data are available regarding the fate and occurrence of ATO in aquatic systems. A monitoring study of statin drugs in a Canadian sewage treatment plant reported concentrations of $76 \mathrm{ng} / \mathrm{L}$ in raw sewage, 37 and $22.4 \mathrm{ng} / \mathrm{L}$ in sewage treatment plant effluents, and $1 \mathrm{ng} / \mathrm{L}$ in surface water $[13,14]$.

The HQ, which was calculated using the exposure data of Miao and Metcalfe [13] and the effects data from the present study, indicates negligible risks of ATO to benthic invertebrates at concentrations currently detected in the environment (Table 4). Calculations using the lowest-effects data from the study by Brain et al. [22] did not change the HQ appreciably, confirming the low risks posed by the presence of this compound.

\section{Carbamazepine}

Carbamazepine was the least toxic of the four chemicals investigated, with LC50s and EC50s ranging from 9.9 to 47.3 $\mathrm{mg} / \mathrm{L}$ (Figs. 1 and 2). Narcosis has been suggested as the main mechanism of action by CBZ in Daphnia magna [9]. The relatively lower toxicity of CBZ compared to the other compounds supports the likelihood that the toxic effect to $C$. tentans and $H$. azteca was also nonpolar narcosis. 
Other studies investigating the effects of CBZ have shown similar toxicity to species from various taxa. Measured toxicity values varied from a 7-d EC50 of $25.5 \mathrm{mg} / \mathrm{L}$ for the macrophyte Lemna minor [9] to a 24-h LC50 of $140 \mathrm{mg} / \mathrm{L}$ for the fairy shrimp Thamnocephalus platyurus [23]. The first published chronic CBZ toxicity study to date was a 28 -d life-cycle assay with spiked sediments, which reported significant effects on Chironomus riparius emergence (EC50, $\approx 0.2 \mathrm{mg} / \mathrm{kg}$ dry wt) [24]. However, concentrations in overlying water were elevated (as high as $2.85 \mathrm{mg} / \mathrm{L}$ ), making it difficult to conclude whether the toxicity resulted from exposure to sediment-bound $\mathrm{CBZ}, \mathrm{CBZ}$ in the overlying water, or both. Indeed, the highest aqueous concentration measured in that study was $2.85 \mathrm{mg} / \mathrm{L}$ [24], which, when compared to those of the present study, would be sufficient to reduce the growth of C. tentans by $10 \%$, as indicated by our $10 \%$ effect concentration of $2.6 \mathrm{mg} / \mathrm{L}$ in a water-only exposure (Table 2). Furthermore, studies in our laboratory have investigated the toxicity of CBZ in spiked sediments using Imhoff sedimentation cones and a water to sediment ratio of 39:1, which ensured minimal aqueous exposure and, thus, permitted evaluation of the specific effect of the sediment-bound compound. No significant toxic effects to either $C$. tentans or $H$. azteca were observed at concentrations as high as $56 \mathrm{mg} / \mathrm{kg}$ dry weight (È.B. Dussault, unpublished results).

Carbamazepine has been detected frequently in sewage effluents and surface water $(82.5-100 \%)$ [3,25], has a long aqueous half-life (82 d) [26], and experiences poor removal during sewage treatment (5-29\%) [3,25]. Reported CBZ concentrations in surface water range from 1.1 to $7,100 \mathrm{ng} / \mathrm{L}$ in Europe $[3,27]$, and similar concentrations have been detected in North America [17,18].

The HQ calculated using the data from the present study (i.e., 0.72) revealed that there was no significant risk to benthic invertebrates (Table 4). We further assessed potential hazard using the chronic toxicity data of Oetken et al. [24], because we suspected that the observed toxicity may have been related to the concentration in the overlying water rather than to the concentration in the sediments. Given that their EC50 was calculated using the concentrations measured in the sediments, however, the former had to be converted from sediment concentration to overlying water concentration, both of which were reported in their study. We therefore used a linear regression predicting the concentration in the water from that in the sediments $\left(y=0.9376 x+0.1975, r^{2}=0.9666\right)$, which yielded an EC50 of $0.385 \mathrm{mg} / \mathrm{L}$. Given the uncertainty associated with the assumption that toxicity was only related to the chemical in the aqueous phase, a UF of 100 was applied. The addition of this calculated value of $0.385 \mathrm{mg} / \mathrm{L}$ resulted in a HQ of 3.55, suggesting that further investigations should be conducted to assess the risk this compound may pose to benthic organisms.

\section{$17 \alpha$-Ethinylestradiol}

The synthetic hormone $\mathrm{EE}_{2}$ was the second most toxic chemical to both species investigated, with 10-d LC50s of 4.1 $\mathrm{mg} / \mathrm{L}$ (C. tentans) (Table 2 and Fig. 1$)$ and $1.1 \mathrm{mg} / \mathrm{L}(H$. azteca) (Table 3 and Fig. 2). Other studies investigating the toxicity of this compound to invertebrates reported a 96-h LC50 of $0.51 \mathrm{mg} / \mathrm{L}$ to the copepod Nitocra spinipes and a 24-h LC50 of $5.7 \mathrm{mg} / \mathrm{L}$ to the cladoceran D. magna [28,29]. Studies with the amphipod Gammarus pulex reported a 10-d 


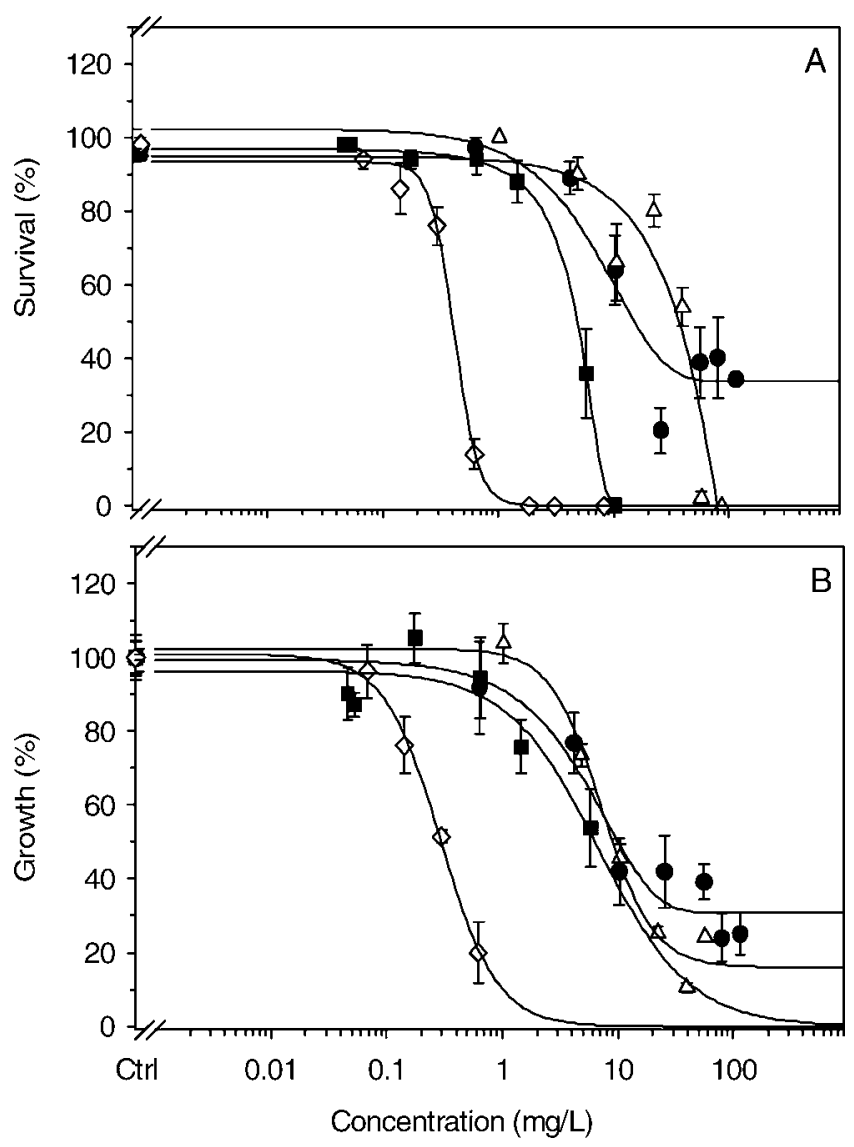

Fig. 1. Survival (A) and growth $(\mathbf{B}$; mean \pm standard error of the mean) of Chironomus tentans following 10-d exposures to four pharmaceutical and personal care products. Trend lines are based on the regression models used for the estimation of median concentrations (see Table 2 ). $=$ atorvastatin; $\triangle=$ carbamazepine; $\mathbf{\square}=17 \alpha$ ethinylestradiol; $\diamond=$ triclosan.

LC50 of $0.84 \mathrm{mg} / \mathrm{L}$ [30], a value similar to those measured in the present study (Tables 2 and 3).

Although the mechanism of action and effects of $\mathrm{EE}_{2}$ are well documented in vertebrates, the role played by sex steroids in invertebrate hormonal control is not as clear. Sex steroids are not known to play a role in the reproduction of insects or crustaceans [31,32]. The process involved with toxicity of $\mathrm{EE}_{2}$ in the present study is not known, but is not likely to be related to its mechanism of action causing endocrine disruption in vertebrates [28].

In contrast with other widespread PPCPs, detection of $\mathrm{EE}_{2}$ in aquatic systems is infrequent, and when detected, environmental concentrations generally are lower than those of other commonly found PPCPs. In 1999 to 2000, a survey of 139 U.S. streams revealed the sporadic presence of $\mathrm{EE}_{2}$ in surface water at concentrations as high as $0.273 \mu \mathrm{g} / \mathrm{L}$, but at a detection frequency of only $5.7 \%$ [33].

The HQ calculated for $\mathrm{EE}_{2}$ yielded values of 0.25 and 0.05 (Table 4), revealing the low risk that this compound may represent for benthic and aquatic invertebrates.

\section{Triclosan}

With 10-d LC50s of $0.4 \mathrm{mg} / \mathrm{L}$ (C. tentans) (Table 2 and Fig. 1) and $0.2 \mathrm{mg} / \mathrm{L}$ (H. azteca) (Table 3 and Fig. 2), TCS was the most toxic of the four compounds tested. Other studies with the cladocerans Ceriodaphnia dubia and D. magna have reported similar sensitivity, whereas some algal species have 

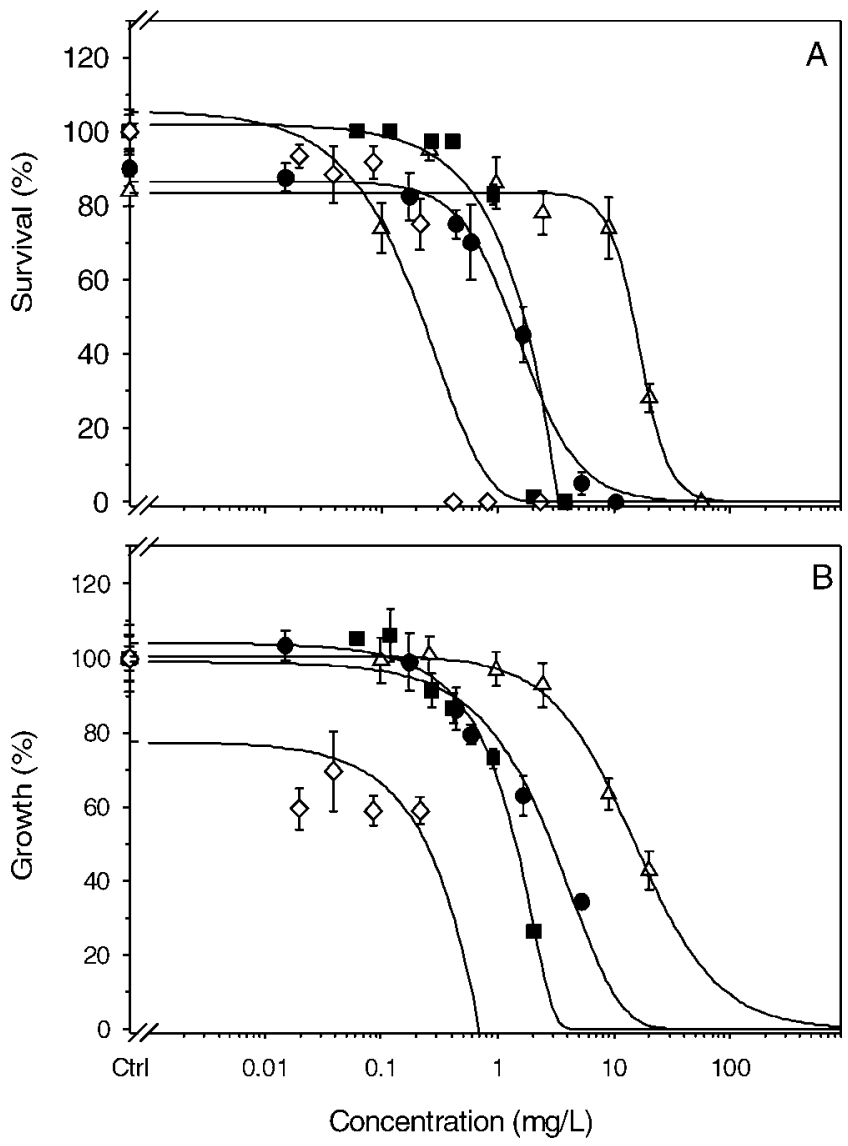

Fig. 2. Survival (A) and growth $(\mathbf{B}$; mean \pm standard error of the mean) of Hyalella azteca following a 10-d exposure to four pharmaceuticals and personal care products. Trend lines are based on the regression models used for the estimation of median concentrations (see Table 3). $=$ atorvastatin; $\triangle=$ carbamazepine; $\square=17 \alpha$ ethinylestradiol; $\diamond=$ triclosan.

been reported to be more sensitive to TCS, with 72- to 96-h EC50s of 0.7 to $4.7 \mu \mathrm{g} / \mathrm{L}$ for Scenedesmus subspicatus, Anabaena flos-aquae, and Pseudokirchneriella subcapitata $[6,7]$.

Despite its usage for more than 35 years, the fate and occurrence of TCS in aquatic environments has mostly been investigated during the last decade. Its widespread addition to numerous household products results in significant release to sewage treatment plants. Although TCS does not appear to resist sewage treatment, with removal of as much as $95.5 \%$ from sewage treatment plants reported [34], the U.S. monitoring survey revealed that TCS was commonly detected in surface water at a frequency of $57.6 \%$ and at concentrations as high as $2.3 \mu \mathrm{g} / \mathrm{L}[2]$.

The HQ for TCS was 11.5, indicating that this compound could pose a risk to benthic invertebrates and that a more thorough risk assessment, including the effects of TCS in sediments, would be required to further elucidate potential risks. The addition of an EC50 from sensitive algae [6] resulted in a HQ of 329, confirming its potential risk and the necessity for undertaking a more complete assessment of the potential impacts this compound may have on aquatic systems.

\section{CONCLUSION}

Our investigations using 10-d survival and growth assays estimated the toxicity of four PPCPs (ATO, CBZ, $\mathrm{EE}_{2}$, and TCS) to the benthic invertebrates $C$. tentans and H. azteca. All four PPCPs were found to be toxic only at concentrations at least 100 -fold greater than those typically detected in aquatic environments. For ATO, $\mathrm{EE}_{2}$, and $\mathrm{CBZ}$, this was reflected in low HQs, ranging from $6.7 \times 10^{-4}$ to 0.72 . In most cases, the addition of data from other studies had little influence on the calculated HQ. For ATO and $\mathrm{EE}_{2}$, the HQ remained below one. For CBZ, however, the use of the data from Oetken et al. [24] resulted in a HQ of 3.55, revealing a potential risk. Triclosan was the only compound for which a HQ greater than one was calculated using the data from the present study, indicating the need for further investigations to fully characterize the risks posed by its presence in aquatic systems. The bioavailability of sediment-bound PPCPs and their potential biological effects on benthic organisms remain largely undetermined and are the subject of current investigations within our laboratory.

Many investigations into the effects of PPCPs have focused on short-term toxicity (e.g., 24- to 96-h toxicity tests) with single substances $[6-8,23]$. Indeed, these studies are simpler and require less time and resources compared with longer chronic toxicity studies. Although acute toxicity testing pro-

Table 4. Hazard quotient for four pharmaceutical and personal care products using effects data from the present study and values reported in the literature $(\mathrm{mg} / \mathrm{L})^{\mathrm{a}}$

\begin{tabular}{|c|c|c|c|c|}
\hline & Atorvastatin & Carbamazepine & $\begin{array}{c}17 \alpha- \\
\text { ethinylestradiol }\end{array}$ & Triclosan \\
\hline Exposure (highest value, surface water) & $0.001^{\mathrm{b}}$ & $7.1^{\mathrm{c}}$ & $0.273^{\mathrm{d}}$ & $2.3^{\mathrm{e}}$ \\
\hline Effects (lowest LC50 for Hyalella azteca) & 1,500 & 9,900 & 1,100 & 200 \\
\hline Uncertainty factor, two species [21] & 1,000 & 1,000 & 1,000 & 1,000 \\
\hline Hazard quotient & $6.7 \times 10^{-4}$ & 0.72 & 0.25 & 11.5 \\
\hline Effects (lowest LC50 or EC50) from other studies & $38^{\mathrm{f}}$ & $385^{\mathrm{g}}$ & $510^{\mathrm{h}}$ & $0.7^{\mathrm{i}}$ \\
\hline Uncertainty factor & 100 & 100 & 100 & 100 \\
\hline Hazard quotient & $2.6 \times 10^{-3}$ & 3.55 & 0.05 & 329 \\
\hline
\end{tabular}

${ }^{\text {a }}$ LC50 and EC50 are the concentration resulting in 50\% mortality or measured effect, respectively.

b Miao and Metcalfe [13].

${ }^{c}$ Wiegel et al. [27].

${ }^{\mathrm{d}}$ Kolpin et al. [34].

${ }^{\mathrm{e}}$ Kolpin et al. [2].

${ }^{\mathrm{f}}$ Brain et al. [22].

$\mathrm{g}$ Value calculated from sediment data from Oetken et al. [24].

${ }^{\mathrm{h}}$ Breitholtz and Bengtsson [28].

${ }^{i}$ Orvos et al. [6]. 
vides much needed answers for the assessment of potential risk, much debate exists regarding its usefulness and validity as an appropriate predictor of potential environmental impacts, because relying solely on this type of data may underestimate potential sublethal effects [10]. Furthermore, given the specific design and inherently high biological activity of PPCPs, one may wonder whether traditional testing methods possess the desired sensitivity to detect the effects of PPCPs. Clearly, further investigations should include chronic toxicity studies [24], which will contribute important information regarding the risks posed by these contaminants in the aquatic environment. Given the current widespread contamination of aquatic systems by numerous pollutants, organisms will most likely be exposed to mixtures of compounds, of which PPCPs represent only a fraction. A few recent studies have focused on evaluating the effects of PPCP mixtures [15,35,36]. In particular, Borgmann et al. [36] investigated the sublethal effects of a mixture of PPCPs on three generations of the amphipod H. azteca, revealing a slight but significant increase in the number of males. These studies raise questions concerning exposure to mixtures of compounds, and they highlight the need to address this issue in future research.

The present study indicates that among the PPCPs investigated, ATO and $\mathrm{EE}_{2}$ pose low risk to benthic invertebrates but that further investigations are needed to provide a more complete assessment of the risk that CBZ and TCS may pose to aquatic invertebrates. Considerable uncertainty exists regarding the potential impacts of chronic exposure to mixtures of these biologically active contaminants. Further long-term studies are needed to fully address the risks and impacts of these compounds on aquatic organisms.

Acknowledgement-The authors thank Monica Lam (University of Toronto, Toronto, ON, Canada) as well as Josey Grabuski, JoAnn Schatschneider, and Donna Zaruk (National Laboratory for Environmental Analysis, Environment Canada, Burlington, ON) for their assistance with analytical chemistry. This research was funded by the Ontario Ministry of Agriculture, Food and Rural Affairs. Additional financial support to E.B.D. was provided by the National Science and Engineering Research Council of Canada and an Ontario Graduate Scholarship.

\section{REFERENCES}

1. Daughton CG, Ternes TA. 1999. Pharmaceuticals and personal care products in the environment: Agents of subtle change? Environ Health Perspect 107:907-938.

2. Kolpin DW, Furlong ET, Meyer MT, Thurman EM, Zaugg SD, Barber LB, Buxton HT. 2002. Pharmaceuticals, hormones, and other organic wastewater contaminants in U.S. streams, 19992000: A national reconnaissance. Environ Sci Technol 36:12021211.

3. Ternes TA. 1998. Occurrence of drugs in German sewage treatment plants and rivers. Water Res 32:3245-3260.

4. Ternes TA, Kreckel P, Mueller J. 1999. Behavior and occurrence of estrogens in municipal sewage treatment plants-II. Aerobic batch experiments with activated sludge. Sci Total Environ 225: 91-99.

5. Ternes TA, Stumpf M, Mueller J, Haberer K, Wilken RD, Servos MR. 1999. Behavior and occurrence of estrogens in municipal sewage treatment plants. I. Investigations in Germany, Canada, and Brazil. Sci Total Environ 225:81-90.

6. Orvos DR, Versteeg DJ, Inauen J, Capdevielle M, Rothenstein A. 2002. Aquatic toxicity of triclosan. Environ Toxicol Chem 21: $1338-1349$.

7. Tatarazako N, Ishibashi H, Teshima K, Kishi K, Arizono K. 2004. Effects of triclosan on various aquatic organisms. Environ Sci 11:133-140.

8. Jos A, Repetto G, Rios JC, Hazen MJ, Molero ML, del Peso A, Salguero M, Fernández-Freire P, Pérez-Martín JM, Cameán A.
2003. Ecotoxicological evaluation of carbamazepine using six different model systems with 18 end points. Toxicol In Vitro 17: 525-532.

9. Cleuvers M. 2003. Aquatic ecotoxicity of pharmaceuticals including the assessment of combination effects. Toxicol Lett 142: 185-194.

10. U.S. Environmental Protection Agency. 2000. Methods for measuring the toxicity and bioaccumulation of sediment-associated contaminants with freshwater invertebrates. EPA/600/R-99/064. Office of Water, Washington, DC.

11. Ternes TA, Andersen H, Gilberg D, Bonerz M. 2002. Determination of estrogens in sludge and sediments by liquid extraction and GC/MS/MS. Anal Chem 74:3498-3504.

12. Cavalucci S. 2006. The top 200: What's making waves in prescription sales. Pharm Pract 22:44-49.

13. Miao X-S, Metcalfe CD. 2003. Determination of cholesterol-lowering statin drugs in aqueous samples using liquid chromatography-electrospray ionization tandem mass spectrometry. J Chromatogr A 998:133-141.

14. Miao X-S, Metcalfe CD. 2003. Determination of pharmaceuticals in aqueous samples using positive- and negative-voltage switching microbore liquid chromatography/electrospray ionization tandem mass spectrometry. J Mass Spectrom 38:27-34.

15. Brain RA, Johnson DJ, Richards SM, Hanson MA, Sanderson H, Lam MW, Young C, Mabury SA, Sibley PK, Solomon KR. 2004. Microcosm evaluation of the effects of an eight pharmaceutical mixture to the aquatic macrophytes Lemna gibba and Myriophyllum sibiricum. Aquat Toxicol 70:23-40.

16. Zaremba PD, Bialek M, Blaszczyk B, Cioczek P, Czuczwar SJ. 2006. Nonepilepsy uses of antiepileptic drugs. Pharmacol Rep $58: 1-12$.

17. Metcalfe CD, Miao X-S, Koenig BG, Struger J. 2003. Distribution of acidic and neutral drugs in surface waters near sewage treatment plants in the lower Great Lakes, Canada. Environ Toxicol Chem 22:2881-2889.

18. Metcalfe CD, Koenig BG, Bennie DT, Servos MR, Ternes TA, Hirsch R. 2003. Occurrence of neutral and acidic drugs in the effluents of Canadian sewage treatment plants. Environ Toxicol Chem 22:2872-2880.

19. Parrott JL, Blunt BR. 2005. Life-cycle exposures of fathead minnows (Pimephales promelas) to an ethinylestradiol concentration below $1 \mathrm{ng} / \mathrm{L}$ reduces egg fertilization success and demasculinizes males. Environ Toxicol 20:131-141.

20. Borgmann U. 2002. Toxicity test methods and observations using the freshwater amphipod Hyalella azteca. NWRI Contribution 02-332. National Water Research Institute, Burlington, ON, Canada.

21. Environment Canada. 1997. Environmental assessments of priority substances under the Canadian Environmental Protection Act. EPS 2/CC/3E. Ottawa, ON.

22. Brain RA, Reitsma TS, Lissemore LI, Bestari K, Sibley PK, Solomon KR. 2006. Herbicidal effects of statin pharmaceuticals in Lemna gibba. Environ Sci Technol 40:5116-5123.

23. Nalecz-Jawecki G, Persoone G. 2006. Toxicity of selected pharmaceuticals to the anostracan crustacean Thamnocephalus platyurus. Environ Sci Pollut Res 13:22-27.

24. Oetken M, Nentwig G, Löffler D, Ternes T, Oehlmann J. 2005. Effects of pharmaceuticals on aquatic invertebrates. Part I. The antiepileptic drug carbamazepine. Arch Environ Contam Toxicol 49:353-361.

25. Miao X-S, Metcalfe CD. 2005. Carbamazepine and its metabolites in wastewater and in biosolids in a municipal wastewater treatment plant. Environ Sci Technol 39:7469-7475.

26. Lam MW, Young CJ, Brain RA, Johnson DJ, Hanson MA, Wilson CJ, Richards SM, Solomon KR, Mabury SA. 2004. Aquatic persistence of eight pharmaceuticals in a microcosm study. Environ Toxicol Chem 23:1431-1440.

27. Wiegel S, Aulinger A, Brockmeyer R, Harms H, Löffler J, Reincke H, Schmidt R, Stachel B, von Tümpling W, Wanke A. 2004. Pharmaceuticals in the river Elbe and its tributaries. Chemosphere 57:107-126.

28. Breitholtz M, Bengtsson BE. 2001. Estrogens have no hormonal effect on the development and reproduction of the harpacticoid copepod Nitocra spinipes. Mar Pollut Bull 42:879-886.

29. Kopf W. 1997. Wirkung endokriner Stoffe in Biotests mit Wasserorganismen. Münchner Beitr Abwasser, Fischerei Flußbiol $50: 82-101$. 
30. Watts MM, Pascoe D, Carroll K. 2001. Survival and precopulatory behavior of Gammarus pulex (L.) exposed to two xenoestrogens. Water Res 35:2347-2352.

31. Nijhout HF. 1994. Insect Hormones. Princeton University Press, Princeton, NJ, USA.

32. Köhler HR, Kloas W, Schirling M, Lutz I, Reye AL, Langen JS, Triebskorn R, Nagel R, Schönfelder G. 2007. Sex steroid receptor evolution and signaling in aquatic invertebrates. Ecotoxicology 16:131-143.

33. Kolpin DW, Furlong ET, Meyer MT, Thurman EM, Zaugg SD, Barber LB, Buxton HT. 2002. Response to comment on "Pharmaceuticals, hormones and other organic wastewater contami- nants in U.S. streams, 1999-2000: a national reconnaissance." Environ Sci Technol 36:4007-4008.

34. Sabaliunas D, Webb SF, Hauk A, Jacob M, Eckhoff WS. 2003. Environmental fate of triclosan in the river Aire basin, UK. Water Res 37:3145-3154.

35. Richards SM, Wilson CJ, Johnson DJ, Castle DM, Lam M, Mabury SA, Sibley PK, Solomon KR. 2004. Effects of pharmaceutical mixtures in aquatic microcosms. Environ Toxicol Chem 23: 1035-1042.

36. Borgmann U, Bennie DT, Ball AL, Palabrica V. 2007. Effect of a mixture of seven pharmaceuticals on Hyalella azteca over multiple generations. Chemosphere 66:1278-1283. 